\title{
Infra-axillary proliferative myositis mimicking a malignant tumor on medical imaging: a case description
}

\author{
Yubizhuo Wang ${ }^{1}$, Wenjie Liang ${ }^{1,2}$ \\ ${ }^{1}$ Department of Radiology, Yiwu Central Hospital, Yiwu, China; ${ }^{2}$ Department of Radiology, The First Affiliated Hospital, Zhejiang University, \\ Hangzhou, China
}

Correspondence to: Wenjie Liang. Department of Radiology, The First Affiliated Hospital, Zhejiang University, No. 79 Qingchun Road, Hangzhou, China. Email: baduen@zju.edu.cn.

Submitted Sep 07, 2020. Accepted for publication Jan 08, 2021.

doi: 10.21037/qims-20-1046

View this article at: http://dx.doi.org/10.21037/qims-20-1046

\section{Case report}

A 47-year-old woman incidentally found a painless mass in her left infra-axillary region 1 week before presenting for treatment. The patient had a 4-year history of diabetes with regular medication, but she denied having a history of trauma, fever, or paresthesia. Physical examination revealed a firm mass in the left lower axillary region. Laboratory results showed that blood routine indicators, including tumor markers, all fell within normal ranges.

Ultrasound examination revealed an irregular hypoechoic nodule without blood flow signal in the subcutaneous soft tissue and the muscular layer of the left chest wall (Figure 1A). An MRI scan was performed to clarify the diagnosis. The results showed a lobulated soft tissue mass measuring $62 \times 32 \times 36 \mathrm{~mm}^{3}$ involving the left serratus anterior muscle with extension into the subcutaneous fat. On fatsuppressed T1-weighted imaging (T1WI), the mass showed isointensity in contrast to the muscle (Figure $1 B$ ), while fat-suppressed T2-weighted imaging (T2WI) revealed diffuse hyperintensity with ill-defined contours (Figure 1C). Contrast-enhanced T1WI with fat suppression showed severe enhancement of the lesion (Figure 1D,F). In view of the above imaging findings, a malignant soft tissue tumor from an axillary accessory breast was suspected. The patient subsequently underwent radical resection of the mass.

Intraoperatively, the tumor was observed to be hard in texture, with an irregular shape and fuzzy boundaries. Furthermore, both the left chest wall muscles and the bottom of the rib were involved. Histopathological examination after the radical resection revealed that fibroblastic and myofibroblastic spindle-cell populations and large ganglion-like cells were present between and around the relatively intact skeletal muscle fascicles in a "checkerboard" pattern (Figure 1G). No histological features of malignancy were observed. Besides, Smooth Muscle Actin (Figure 1H), vimentin, and desmin (Figure 1I) were positive. Finally, a diagnosis of proliferative myositis (PM) was confirmed by pathology. No recurrence was detected in the surgical area during the short-term follow-up.

PM, which was first described by Kern in 1960, is a rare benign lesion (1). A typical pathological finding of $\mathrm{PM}$ is that the cells proliferate to replace a section of the adjacent muscular tissues in a "checkerboard" pattern (2). PM typically occurs in the extremities and shoulders, as well as in the head and neck (3-9). It shows no obvious sex preference, and the average age at onset is $\geq 50$ years $(3,4)$. Clinically, PM usually manifests as a subcutaneous isolated mass with rapid growth or regional pain (2-9). Only a single case of PM occurring at the chest walls near the left chest bone has been documented (2). In the current case, the PM occurred at the infra-axillary region of the left chest wall. To our knowledge, this is the first reported case of PM occurring in this region.

The previously reported PM cases were almost all isolated soft tissue masses, with sizes between $0.5 \times 0.5$ and $5 \times 7 \mathrm{~cm}^{2}$ (2-9). On ultrasound imaging, PM can manifest as a hypoechoic lesion with a "cracked dry mud" pattern outlined by muscle fibers $(5,7,8)$. On CT, the affected muscles can appear swollen, and the lesion is isodense, with different degrees of enhancement $(2,4,7,8)$. Manifestations 

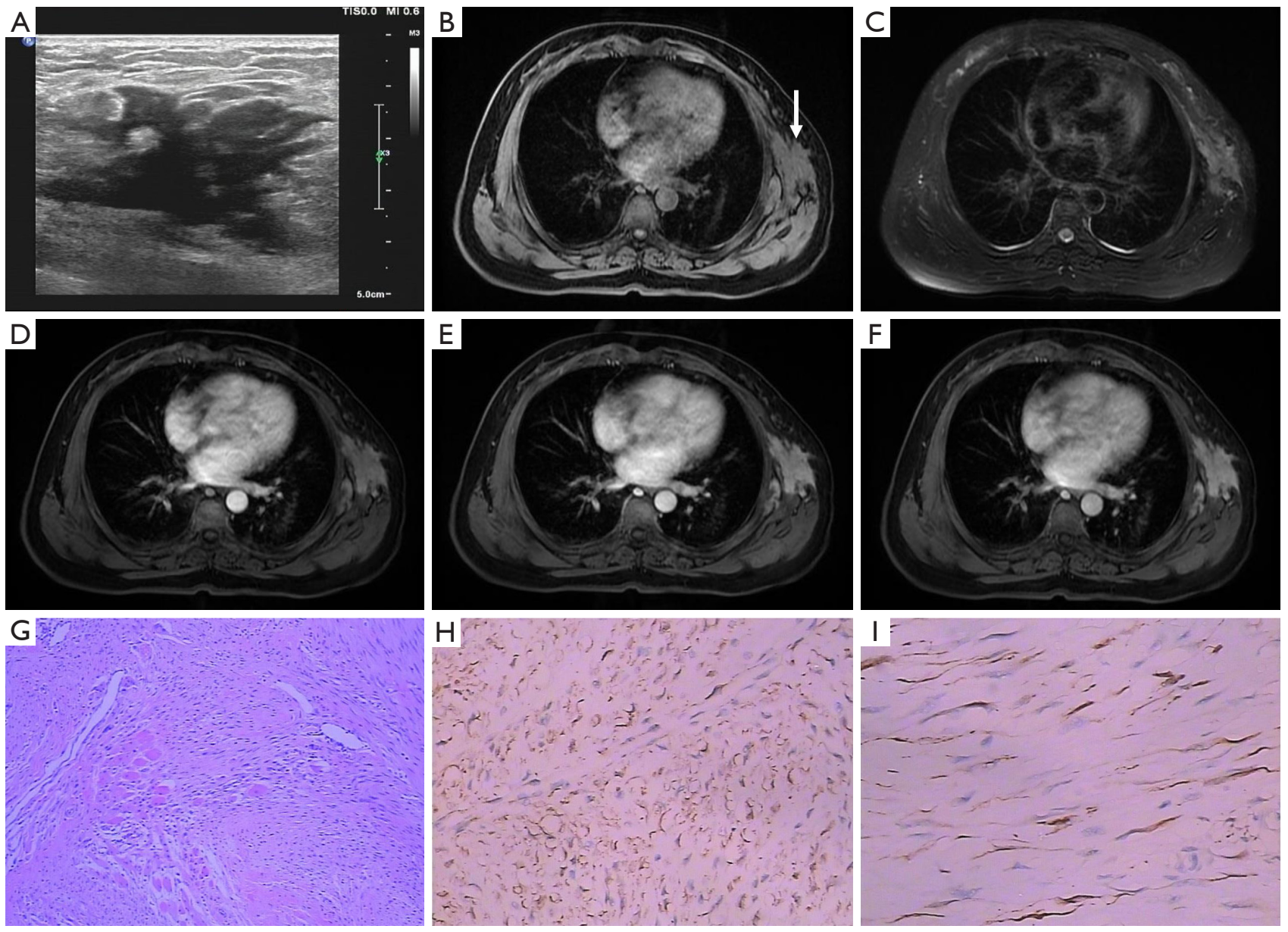

Figure 1 Proliferative myositis mimicking a malignant tumor. (A) Ultrasound image showing an ill-defined hypoechoic lesion with a crab's foot appearance. MRI reveals a soft tissue mass at the left axillary boundary, with an isointensity signal on fat-suppressed T1weighted imaging (B), a hyperintensity signal on fat-suppressed T2-weighted imaging (C), and progressive enhancement (D-F). (G) Pathological results show spindle-cell proliferation among muscle fibers with a checkerboard pattern (hematoxylin-eosin staining, $\times 100$ ). Immunohistochemical staining shows that smooth muscle actin $(\mathrm{H})$ and desmin $(\mathrm{I})$ were positive in tumor cells $(\times 400)$.

on T1WI MRI include isointensity to muscle, while T2WI can show ill-defined hyperintensity mixed with sheetlike hypointensity (4-8). Although the lesions are usually manifested by severe enhancement (4-7), 1 documented case showed only mild enhancement (8). A large PM lesion can also present with adjacent fascias (5). MRI is considered valuable for PM as it can depict the preserved muscle fibers, while CT features are considered to be nonspecific. In our case, neither the T2WI nor the contrastenhanced images showed geometric patterns composed of muscle fibers. However, the patchy hypointensity signal on T2WI was similar to that in a case of PM reported in a child (8). Therefore, we recommend that PM be included as a possible diagnosis for patients with a mass with T2WI hypointense signals. Additionally, the present PM case showed progressive enhancement, which has not been reported in the literature previously. The details of this case indicate that clinicians must be familiar with the typical and atypical imaging features of PM so as to reduce misdiagnosis and develop appropriate treatment strategies.

In the past, PM was often misdiagnosed as a malignant tumor and treated with surgical resection (3). However, more recently, relatively conservative therapeutic strategies, including "wait and watch" and local excision, have been advocated, since this disease has shown to be self-limiting and rarely exhibits malignant biological behavior (9). The differential diagnosis includes nodular fasciitis, inflammatory myopathies, and diabetic myonecrosis (10). 
Nodular fasciitis usually presents as small painful nodules in the subcutaneous tissues. The typical manifestation of inflammatory myopathies is symmetric proximal muscles involved in 2 subtypes: dermatomyositis and polymyositis. Lastly, diabetic myonecrosis always occurs in poorly controlled diabetic patients, and often extensively involves the muscles of both lower limbs. Our case underwent radical surgery for the possibility of malignancy in preoperative imaging evaluation. However, to reduce unnecessary surgery and complications, biopsy should be the preferred tool for suspected PM.

\section{Acknowledgments}

Funding: None.

\section{Footnote}

Conflicts of Interest: Both authors have completed the ICMJE uniform disclosure form (available at http://dx.doi. org/10.21037/qims-20-1046). The authors have no conflicts of interest to declare.

Ethical Statement: The authors are accountable for all aspects of the work in ensuring that questions related to the accuracy or integrity of any part of the work are appropriately investigated and resolved. All procedures performed in studies involving human participants were in accordance with the ethical standards of the institutional and/or national research committee(s) and with the Helsinki Declaration (as revised in 2013). Written informed consent was obtained from the patient for publication of this study and any accompanying images. A copy of the written consent is available for review by the Editor-in-Chief of this journal.

Open Access Statement: This is an Open Access article distributed in accordance with the Creative Commons Attribution-NonCommercial-NoDerivs 4.0 International License (CC BY-NC-ND 4.0), which permits the non- commercial replication and distribution of the article with the strict proviso that no changes or edits are made and the original work is properly cited (including links to both the formal publication through the relevant DOI and the license). See: https://creativecommons.org/licenses/by-nc-nd/4.0/.

\section{References}

1. Kern WH. Proliferative myositis; a pseudosarcomatous reaction to injury: a report of seven cases. Arch Pathol 1960;69:209-16.

2. Kent MS, Flieder DB, Port JL, Altorki NK. Proliferative myositis: a rare pseudosarcoma of the chest wall. Ann Thorac Surg 2002;73:1296-8.

3. Brooks JK, Scheper MA, Kramer RE, Papadimitriou JC, Sauk JJ, Nikitakis NG. Intraoral proliferative myositis: case report and literature review. Head Neck 2007;29:416-20.

4. Gan S, Xie D, Dai H, Zhang Z, Di X, Li R, Guo L, Sun Y. Proliferative myositis and nodular fasciitis: a retrospective study with clinicopathologic and radiologic correlation. Int J Clin Exp Pathol 2019;12:4319-28.

5. Pagonidis K, Raissaki M, Gourtsoyiannis N. Proliferative myositis: value of imaging. J Comput Assist Tomogr 2005;29:108-11.

6. Demir MK, Beser M, Akinci O. Case 118: Proliferative myositis. Radiology 2007;244:613-6.

7. Yiğit H, Turgut AT, Koşar P, Astarci HM, Koşar U. Proliferative myositis presenting with a checkerboard-like pattern on CT. Diagn Interv Radiol 2009;15:139-42.

8. Talbert RJ, Laor T, Yin H. Proliferative myositis: expanding the differential diagnosis of a soft tissue mass in infancy. Skeletal Radiol 2011;40:1623-7.

9. Colombo JR, Dagher W, Wein RO. Benign proliferative myositis of the sternohyoid muscle: review and case report. Am J Otolaryngol 2015;36:87-9.

10. Hayeri MR, Ziai P, Shehata ML, Teytelboym OM, Huang BK. Soft-Tissue Infections and Their Imaging Mimics: From Cellulitis to Necrotizing Fasciitis. Radiographics 2016;36:1888-910.
Cite this article as: Wang Y, Liang W. Infra-axillary proliferative myositis mimicking a malignant tumor on medical imaging: a case description. Quant Imaging Med Surg 2021;11(9):4216-4218. doi: 10.21037/qims-20-1046 